\title{
Brain delivery of proteins via their fatty acid and block copolymer modifications
}

\author{
Xiang $\mathrm{Yi}^{1}$ and Alexander V. Kabanov ${ }^{1,2}$ \\ ${ }^{1}$ Division of Molecular Pharmaceutics and Center for Nanotechnology in Drug Delivery, UNC \\ Eshelman School of Pharmacy, University of North Carolina at Chapel Hill, Chapel Hill, NC, USA \\ 2Laboratory for Chemical Design of Bionanomaterials, Faculty of Chemistry, M.V. Lomonosov \\ Moscow State University, Moscow, Russia
}

\begin{abstract}
It is well known that hydrophobic small molecules penetrate cell membranes better than hydrophilic molecules. Amphiphilic molecules that dissolve both in lipid and aqueous phases are best suited for membrane transport. Transport of biomacromolecules across physiological barriers, e.g. the blood-brain barrier, is greatly complicated by the unique structure and function of such barriers. Two decades ago we adopted a simple philosophy that to increase protein delivery to the brain one needs to modify this protein with hydrophobic moieties. With this general idea we began modifying proteins (antibodies, enzymes, hormones, etc.) with either hydrophobic fatty acid residues or amphiphilic block copolymer moieties, such as poy(ethylene oxide)-poly(propylene oxide)-poly(ethylene oxide) (pluronics or poloxamers) and more recently, poly(2-oxasolines). This simple approach has resulted in impressive successes in CNS drug delivery. We present a retrospective overview of these works initiated in the Soviet Union in 1980s, and then continued in the United States and other countries. Notably some of the early findings were later corroborated by brain pharmacokinetic data. Industrial development of several drug candidates employing these strategies has followed. Overall modification by hydrophobic fatty acids residues or amphiphilic block copolymers represents a promising and relatively safe strategy to deliver proteins to the brain.
\end{abstract}

\section{Keywords}

Blood-brain barrier; brain delivery; copolymer; drug delivery; peptide; pharmacokinetics; polymer

\footnotetext{
(C) 2013 Informa UK Ltd.

Address for correspondence: Alexander Kabanov, University of North Carolina at Chapel Hill, Molecular Pharmaceutics, 120 Mason Farm Road, Chapel Hill, NC 27599, USA. kabanov@email.unc.edu.

Declaration of interest

The authors acknowledge the support of the American Heart Association Pre-Doctoral Fellowship 0910040G (to X.Y.), the National Institutes of Health RO1 NS051334, the Center of Biomedical Research Excellence (CoBRE) Nebraska Center for Nanomedicine P20 GM103480 (P20 RR021937), as well as the Russian Ministry of Science and Education Megagrant award (Contracts 11.G34.31.0004). The authors report no conflicts of interest. The authors alone are responsible for the content and writing of this article.
} 


\section{Introduction}

The challenge of the delivery of the therapeutic proteins to the brain is well recognized. Poor serum bioavailability of many proteins during systemic circulation combined with their low permeability across the blood-brain barrier (BBB) tremendously limit the effective amounts of these proteins that can enter the brain. Extensive efforts have been devoted to improve protein delivery to the brain to address various diseases of the central nervous system (CNS) as reviewed herein and elsewhere [1-5]. Thus, intranasal administration, for example, has recently become a promising strategy to deliver proteins and other biotherapeutics to the brain as it allows bypassing the BBB and minimizing peripheral tissue exposure [6-9]. Another recent example is the use of a bispecific antibody with low-binding affinity to the transferrin receptor, which displays high permeability across the BBB (contrary to the high affinity antibodies that are entrapped in the brain endothelium) [10,11]. Moreover, there is a growing effort in using nanotechnologies in the CNS delivery field, which aims to improve stability and pharmacokinetics (PK) of proteins by encapsulating them in nanoparticles and further increase their brain uptake using BBB specific targeting moieties [12-20]. The field keeps moving forward as the investigators gain better understanding of the BBB biology and acquire experience in developing delivery systems for CNS diseases.

This paper reviews some of our own efforts to deliver proteins to the brain, involving chemical modification of proteins by fatty acid residues and block copolymer amphiphiles. Along with retrospective overview of these studies spanning over two decades this paper covers multidisciplinary approaches ranging from synthesis, cell entry and trafficking, PK and brain distribution, and finally to the evaluation of efficacy in relevant CNS disease models. While continuing our work to improve protein delivery to the brain, we aim to share the knowledge and experience of the state of the art in each of these approaches, which hopefully will disseminate and advance an in-depth understanding of these strategies for protein delivery to the brain.

\section{Artificial fatty acid acylation of proteins}

Fatty acid acylation is a common step in endogenous modification of proteins serving to regulate protein interaction with membranes and influence protein sorting within cells [2124]. In early $80 \mathrm{~s}$ Torchilin's group has applied artificial lipid and fatty acid modification of proteins to immobilize them within the liposomal membranes [25]. The idea of artificial hydrophobization of proteins by fatty acid residues to enhance protein delivery into cells and to the brain goes back to late 1980s [26-28]. Such fatty acylated proteins exhibit increased ability to anchor to cell membranes (which sometimes involves interaction with fatty acid binding membrane proteins) and enhanced internalization in cells [29]. This seems to remain true in the case of the brain microvessel endothelial cells (BMEC), which comprise the BBB. Interestingly, early work by the Chekhonin and Kabanov groups showed that fatty acid acylation only improved brain accumulation of the proteins that can specifically bind with the receptor expressed within the brain [26]. For those brain non-specific proteins, the fatty acid acylation resulted in increased accumulation in liver rather than in the brain. This was evidenced by $\mathrm{C} 18$ fatty acid (stearic acid) acylation of two brain specific antibody fragments, Fab against glial fibrillary acidic protein (Fab-GFAP) and Fab against a2- 
glycoprotein (Fab-a2-GP), and two brain non-specific antibody fragments, Fab against a 1 and $a 2$ human globulins (Fab-a 1-IgG and Fab-a2-IgG). To examine the therapeutic response, a neuroleptic drug, trifluoperazine, was attached to these antibody fragments. Intracarotid injection of iodine labeled stearylated Fab- GFAP and Fab-a2-GP to rat model showed significantly increased (versus unmodified Fab-GFAP and Fab-a2-GP) accumulation of the modified fragments in the brain, followed by in the heart and in the lung. In contrast iodinated stearylated Fab-a 1-IgG and Fab-a2-IgG distributed much better (versus unmodified Fab-a 1-IgG and Fab-a2-IgG) in the liver, followed by in the spleen and in the lung. The pharmacodynamic response appeared to corroborate the PK data as a drastic increase of the neuroleptic activity was observed only with the stearylated brain specific antibody fragments. Slepnev and Kabanov followed-up these in vivo works and further examined in various of mammalian cell models how fatty acylated horseradish peroxidase (HRP), a membrane impermeable enzyme and a well known endocytosis marker, interacted with cells [29]. They confirmed that fatty acylation increased cellular binding and internalization of HRP, to a greater extent in the presence of serum (than without serum) and at $4{ }^{\circ} \mathrm{C}$ (than $37^{\circ} \mathrm{C}$ ). Internalized fatty acylated HRP was mainly distributed in endocytic vesicles and less noticeable in cytoplasm [29]. In a transport study using bovine BMEC (BBMEC) monolayer, Chopineau demonstrated that the permeability of monoacylated ribonuclease A correlated with the length of the acyl chain; as the carbon chain became longer the permeability across the cell monolayer increased [30]. Subsequently, the Kabanov and Banks groups reported on the brain PK of fatty acylated HRP [31]. They demonstrated that stearylated HRP was able to cross the BBB at a higher influx rate than native HRP. The serum half-life was not altered by fatty acylation. Direct measurement of liver accumulation was not reported in this paper. However, based on the serum clearance curve, the volume of distribution of stearylated HRP was much higher than that of the native HRP, suggesting that the stearylated protein sequestered in tissues. Again, a minimum increase was seen in brain uptake, consistent with what was shown previously for non-specific brain antibodies [26].

Interest to protein delivery to the brain using fatty acylation was dampened by an additional challenge encountered at that time: experimental difficulties in attaching hydrophobic fatty acids to water-soluble proteins. Reacting hydrophobic reagent with hydrophilic protein generally does not proceed well in an aqueous medium even in the presence of a detergent (e.g., sodium cholate) (Figure 1A and B). Indeed, only $20 \%$ of a-chymotrypsin was modified by stearoyl chloride in water and the modified fraction was highly heterogeneous containing from 6 to 12 stearoyl groups per protein molecule [27]. Reacting protein/peptide with fatty acid directly in organic solvent is not recommended because of protein inactivation and solubility issues (Figure 1C). Modification was then carried out in aqueous microemulsions stabilized by a surfactant, sodium bis-(2-ethylhexyl) sulfosucciate (Aerosol OT) in the water-immiscible organic solvent, octane [32,33] (Figure 1D). In such microheterogeneous medium also sometimes termed "hydrated reverse micelles" at the same molar ratio of stearoyl chloride to proteins, more than $80 \%$ protein was modified with 1 to 2 stearoyl groups per protein [27]. Unfortunately exposing proteins to organic solvents in this reverse micelles system led to a significant loss of the activity for most of proteins. Only 15$25 \%$ of the activity remained in fatty acylated trypsin [27], 50\% in stearoylated HRP [29] 
and $60-80 \%$ in stearoylated a-chymotrypsin [27]. Additionally, removal of the remaining surfactant from the final fatty acylated proteins was not trivial, albeit realizable by precipitation in acetone and chromatography method [34].

Nevertheless, the effort to develop fatty acylated proteins has continued and not surprisingly, was more appreciated for treating peripheral diseases or conditions where the peripheral pathological mechanism is partially involved. Soviet Union researchers continuously carried out the work by modifying pig leukocyte interferon with steroid acid using similar reverse micelle systems. Following i.v. administration in poultry and cattle, the modified interferon showed a drastic decrease in viral titer (up to a million fold) and a significant improvement in its protective activity against various pathogens, in comparison to animals treated with interferon alone [32]. Investigators also noted nearly a thousand-fold decrease in the proliferation of human Jurkat T-lymphoma cells upon treatment with palmitoylated human recombinant a 2 -interferon versus incubation with native a 2 -interferon [35]. Similarly, the toxic effect of Staphylococcus aureus enterotoxin A on Jurkat Tlymphoma and peripheral blood lymphocytes was considerably amplified when enterotoxin A was modified by strearic acid [36]. In the same publication, the author also demonstrated that stearylated ricin A chain, a protein that was initially inactive due to lack of penetration into cells, acquired considerable activity in inhibiting protein biosynthesis and cell proliferation in the lymphoma cells. This provided additional evidence that fatty acylation of selected proteins can increase their transport into cells.

With this rationale Kabanov et al. used the fatty acylation approach to increase antiviral activity of the antibodies against several viruses. Thus, stearylation of polyclonal and monoclonal antibodies against the influenza virus hemagglutinin (HA) and the influenza virus nucleoprotein (NP) suppressed the reproduction of various influenza viruses by one to three orders of magnitude in the infected cell culture [37]. A similar phenomenon was observed using the stearylated polyclonal antibodies against the respiratory syncytial virus, which displayed decreased capability to infect MDCK cells compared to that of unmodified antibodies. It was proposed that by anchoring in the membranes of virus-infected cells through the fatty acid moieties, the modified antibodies were able to interfere with the selfassembly and/or budding of the respective viral particles. Furthermore, the attenuation of viral growth in the infected cells could also attribute to the penetration of modified antibody into the cells and thereby serve as an intracellular antigen to interfere with the virus cycle. Subsequent animal studies further supported the therapeutic improvement for fatty acylated antibodies against virus infection. The effect of stearylated or unmodified monoclonal antibodies against the glycoprotein gD of the herpes simplex virus 1 (HSV1) was evaluated in pre-infected mice that developed lethal herpetic meningitis or generalized herpetic infection. Following intracerebral injection (to treat meningitis) or intraperitoneal injection at various doses for $5 \mathrm{~d}$ (to treat generalized infection), the modified antibodies decreased the mortality in both disease models by about $60 \%$, while the effects of the unmodified antibodies did not exceed $30 \%$. In spite of the observed improvement in both in vitro and in vivo studies we listed above, the fundamental mechanism of fatty acylation to facilitate protein therapeutics has not been well illustrated. 
More recently, development of fatty acylated proteins have focused on treatment of liver diseases, which is rationalized by the liver targeting effect as a consequence of fatty acylation. Wei-Chiang Shen and colleagues introduced four C16 fatty acid (palmitic acid) moieties to the cysteine amino acids of interferon $a$, a most effective antiviral agent for chronic viral hepatitis [38]. The reaction appeared to proceed well in phosphate saline buffer supplemented by $0.5 \%$ Chaps detergent. About $90 \%$ of the protein was modified and no dramatic changes were observed in the secondary structure of the modified interferon $a$, albeit its remaining activity was not reported. Following fatty acylation, intravenous administration of iodinated interferon a showed much longer serum circulation and higher liver accumulation than the native form. The augmentation of the in vivo antiviral effect was also demonstrated in mice receiving fatty acylated interferon. It probably would be more appealing if these studies included the comparison with PEGylated interferon $a$, the most widely used product for liver hepatitis. Provided the liver-targeting effect and the capacity to be taken up by hepatocytes are exhibited in the fatty acylated interferon a, it could be a promising candidate to treat liver hepatitis [38]. A study conducted by Kathrin BellmannSickert using pancreatic polypeptide (PP) as an example could partially highlight the advantage of lipidation over PEGyation to target proteins to the liver [39]. In this study the modification of PP by a single palmitoyl moiety resulted initially in increased high blood content of the modified peptide followed by its tissue sequestration throughout the whole body with predominant localization in the heart and finally distribution of this peptide exclusively in the liver. In contrast, native PP or PP modified with PEG (2 KDa) was exclusively excreted from the kidney, resulting in a much shorter plasma residence than that of palmitoylated PP.

The examples of fatty acid acylated proteins for brain delivery are presented in Table 1. As of today perhaps the most advanced application of artificial fatty acid acylation of proteins for drug delivery is the development of long acting anti-obesity hormones. Gut-brain hormones originate from the gut-intestine tissue and act partially or exclusively within the CNS to control appetite and energy consumption. These polypeptide hormones often have less than 30 amino acids. They exert their biological function either via systemic circulation and delivery into the brain and/or communicating with the brain via the vagal nerve [50]. There is a growing awareness that these hormones along with circulating nutrients and neuronal peptides modulate appetite, feeding and metabolism [51-54]. Therefore they provide a range of therapeutic opportunities for treatment of metabolic disorders (e.g diabetes, obesity, etc.) $[55,56]$. Interestingly, fatty acid acylation of gut-brain hormones is a naturally occurring phenomenon. Octanoic acid acylated ghrelin, 28-amino acid peptide, acts as an important cognate ligand to stimulate growth hormone release and regulate energy hemostasis [42]. Specifically, O-n-octanoylation of ghrelin at the serine 3 position, a posttranslational reaction catalyzed by ghrelin O-acyltransferase (GOAT) (Figure 1E), is indispensible for the hormone binding to and activation of the growth-hormone secretagogue receptor [41,44]. This is an essential step in initiating the multifaceted endocrine function of ghrelin. It appears that the pharmacological role of the post-translational modification of ghrelin with octanoic acid mainly involves the modulation of the hormone-receptor interactions rather than altering the $\mathrm{PK}$ of the hormone and its passage across the $\mathrm{BBB}$ $[40,43]$. However, the brain PK study did show that octanoylation of ghrelin has a dramatic 
effect on its transport characteristics across the BBB [40]. Although the improved brain delivery of the octanoylated ghrelin so far was not implicated in its physiological function, the fact that such natural modification takes place negates some safety concerns for fatty acylation of polypeptides and sheds light on the potential to influence their brain PK using this approach.

Moreover, since short sequence peptides are produced by solid-phase synthetic strategies, the fatty acid chains can be introduced in the gut-brain hormones in a robust and controllable fashion during the peptide synthesis circle followed by cleavage of the modified peptide from the resin, allowing for a clean product with minimum activity loss [39,48] (Figure 1F). This is an important factor that has facilitated and possibly will continuously inspire development of fatty acylated gut-brain hormones as therapeutic drugs. Liraglutide, a glucagon-like peptide 1(GLP-1) analog modified with a C16 fatty acid chain is currently tested in Phase III as an anti-obesity drug [46,57]. Owing to the notable improvement in its PK profile (longer circulation, smaller volume distribution), this daily subcutaneously administered GLP-1 analogue is a promising drug candidate to replace exenatide, a native form of GLP-1, which must be given twice daily. It is beyond the scope of this article to compare in-depth the efficacy and risk of liraglutide and exenatide. Simply saying, the efficacy of liraglutide seems to improve while there was not an identifiable decrease in polypeptide tolerability [45,46]. Interestingly, most of the gut-brain hormones including GLP-1 control appetite and thermogenesis at two sites: peripherally by signaling the vagal nerve surrounding gut-intestine and centrally by simultaneously acting at their central receptors after circulating to the brain. Animal studies have provided clear evidence that the anti-obesity effect of exogenously delivered exenatide and liraglutide was a combination of their action at both peripheral and central sites [47]. However, in spite of improvement in the hormone's peripheral circulation, no brain PK data were reported to support the role of fatty acylation to increase GLP-1 brain uptake.

Nevertheless, the strategy has been extended to deliver a-melanocyte-stimulating hormone (a-MSH), a tetradecappeptide that acts within the brain and regulates energy expenditure via melanocortin system. To overcome the short serum half-life of native a-MSH, Novo Nordisk developed an a-MSH analog with N-terminal attachment of the C16 fatty acid [48]. The serum half-life of a-MSH as a result of its modification with palmitic acid was increased allowing for a once-daily injection of the modified hormone to attain adequate therapeutic response. In an acute feeding study, this long acting a-MSH analog displayed a prolonged response of food reduction following a single subcutaneous administration in normal body weight male Sprague-Dawley rats ( $48 \mathrm{~h}$ versus $7 \mathrm{~h}$ in unmodified hormone). Albeit the brain PK study on this palmitoylated a-MSH was not reported, Novo Nordisk conducted the preclinical and clinical studies of fatty acylated a-MSH named MC4NN2-0453 in obese model. While in obese mini-pigs, MC4-NN2-0453 showed a better response than unmodified a-MSH in reduction of energy expenditure and food intake, the clinical trial of this fatty acylated a-MSH analog, however, did not show any clinically meaningful change in obese patients and did not succeed due to the pharmacological side effect associated with hyperpigmentation [49]. Development of other anorexigenic neuropeptides by fatty acylation is also underway. Prolactin-releasing peptide (PrP), a 31 amino acid anorexigenic neuropeptide acts exclusively in the brain to regulate energy 
expenditure. Maletinska et al. produced a fatty acylated PrPR in order to elongate the circulation circulation time of this polypeptide and increase its permeability at the BBB. The data were reported as a conference abstract showing fatty acylated PrPR had stronger effects in fasted mice following subcutaneous administration [58].

Despite growing evidence that fatty acylation improves protein therapeutics acting at both peripheral and central sites, understanding the mechanism of the increased transport of fatty acylated proteins at the BBB level lagged behind. Fatty acylation as an endogenous process to regulate the reversible membrane association and intracellular signaling has been well elucidated [23]. Strongly depending on the attached fatty acid (type, length, the amount per protein) and the nature of protein (charge, binding ligand, phosphorylation, co-factor), fatty acylated endogenous proteins penetrate the cell membranes in various manners, with different efficiencies, and have various destinations inside cells [23]. To advance the delivery for brain targeting, there is a need to understand how these mechanisms come into play at the brain endothelium level. For example, the binding of fatty acylated proteins to cell membrane is generally driven by hydrophobic interactions. At the BBB, a transportermediated mechanism might play a role when the attached fatty acids, such as linoleic acid, are naturally transferred to the brain by transporters $[59,60]$. The luminal side of the brain endothelium is often negatively charged. This should be taken into account as an additional way to facilitate the penetration of fatty acylated proteins across the BBB. For example, cellular binding might increase when the modified protein itself contains a polybasic motif which in addition to lipid carrier serves as an anchor generating stable and sufficient hydrophobic interactions with cell membrane [23]. Furthermore, most free fatty acids are bound to albumin. It is conceivable that circulating fatty acylated proteins bind with albumins as well, which can affect the PK profile and subsequent BBB penetration. Moreover, the brain PK profile and brain region distribution of the fatty acylated proteins could be significantly affected by possible interactions of the fatty acid residues with the intrinsic receptors for the fatty acids in the CNS. For example, free fatty acids can activate an endogenous G protein-coupled receptor (GPCR), which acts as a nutrient sensing apparatus to regulate nutrient balance [61]. Some of the GPCRs are expressed in the brain [62]. However, the concentration of the circulating fatty acylated proteins may be below the micromolar level, a concentration needed for the receptor activation. This would negate a possibility of potential side effects of the fatty acylated proteins associated with the effect on the GPCRs.

\section{Polymer-protein conjugates}

Conjugation of proteins with natural and synthetic polymers has been researched for several decades and led to important pharmaceutical products. Many studies have focused on modification of proteins with hydrophilic oligosaccharides such as polysialic acid (PSA), [63] dextrin [64-67] hyaluronic acid [68] as well as water-soluble synthetic polymers such as N-(2-hydroxypropyl)-methacrylamide (HPMA) [69] and poly(ethylene) glycol (PEG) [70-79]. Most of these protein-polymer conjugates displayed prolonged circulation time and improved stability as compared to native proteins. One of the early examples of such conjugates is Streptodecase, which represents streptokinase, a plasminogen activator enzyme, immobilized on a polysaccharide dextran carrier [25]. Streptodecase has been 
marketed since 1980 in Soviet Union (and then in Russia) as an injectable long-acting fibrinolytic drug. In 1982a group of scientists including Vladimir Torchilin was awarded the USSR Lenin prize for the development of immobilized enzyme therapeutics for heart diseases, such as Streptodecase.

Perhaps to date the most successful approach to improve bioavailability of proteins through their conjugation with water-soluble polymers is the covalent modification of proteins with PEG chains, known as "PEGylation". Frank Davis and colleagues have pioneered PEGylation in the 1970s [71]. Using catalase and albumin as model proteins, they showed that attachment of PEG (1900 or $5000 \mathrm{Da}$ ) to these proteins prolonged their circulation, increased their serum stability and reduced their immunogenicity [80,81]. Since then PEGylation has been widely used to modify various proteins and has tremendously helped advance the development of novel protein therapeutics [63]. In 1981 Dr Davis and his former student Dr Abraham Abuchowski founded Enzon Corporation, which became publicly traded in 1984 and then brought to the market the first two PEGylated protein products, PEG-adenosine deaminase in 1990 and PEG-L-asparaginase in 1994. Following this breakthrough over a dozen of PEGylated protein drugs have been approved for clinical use in the United States and other countries (Table 2).

Conjugation of proteins with hydrophobic polymers for medical applications has been relatively less researched. One polymer-protein conjugate brought to market in Japan in 1990s was neocarzinostatin (NCS) conjugated with hydrophobic poly(styrene-co-maleic acid) (SMA) [82-84]. The drug is also known as Zinostatin or Smancs and is marketed in Japan by Astellas Pharma. It was developed by Hiroshi Maeda and colleagues who intended to prolong the circulation time of NCS for the improvement of its antitumor activity. The modified NCS was dissolved in its oil-based carrier Lipidol and administered via hepatic artery injection as an oily formulation. Higher hydrophobicity of SMANCS appeared to result in a much longer circulation of NCS, efficient accumulation of NCS in both tumor and lymphatic tissue and improvement in its antitumor activity against hepatocellular carcinoma [84]. Following-up studies from the same group and others further showed that SMA modification increased serum circulation of human granulocyte colony-stimulating factor (rhG-CSF), cell adhesive laminin peptide YIGSR and superoxide dismutase (SOD) [85-87]. It is noteworthy that different from PEGylation, the prolonged in vivo plasma half-life of SMA modified proteins was mostly attributed to the non-covalent albumin binding of its attached SMA polymer, which thereby prevented a rapid renal excretion [88]. Whether or not such modification improves the delivery of protein to the brain, however, has not been reported.

Despite progress in development of protein conjugates with hydrophilic and hydrophobic polymers it had not been until relatively recently when the amphipihlic block polymers containing both hydrophilic and hydrophobic chains were first used for chemical modification and delivery of proteins. However, once implemented this approach resulted in unexpected and important consequences in polymer therapeutics, particularly in delivering proteins to the brain, which is described later. 


\section{Proteins modified with amphiphilic Pluronic block copolymers}

Pluronic molecule consists of poly(ethylene oxide) (PEO, same as PEG) and poly(propylene oxide) (PPO, same as PPG) segments arranged in a basic A-B-A structure: PEO-PPO-PEO (Table 3, A). These commercially available polymers are widely used in a variety of clinical applications and are listed in the U.S. and British Pharmacopoeia under the name "poloxamers" as excipients. Changing the number of ethylene oxide and propylene oxide units generates a variety of polymers differing in size, molecular mass and hydrophobicity. Above certain critical temperatures the PPO chains become insoluble and tend to aggregate in aqueous media while the PEO chains can remain soluble. As a result, a unique feature of Pluronic molecules is their ability to self-assemble into micelles above the critical micelle temperature (CMT) and critical micelle concentration (CMC), or to form temperatureresponsive gels at relatively high concentrations.

The use of Pluronic block copolymers in pharmaceutical formulations has a long history. Such formulations include Pluronic-based gels and blends used in delivery and sustained release systems for low molecular mass drugs and biomacromolecules, including proteins [95]. The surface-active properties of Pluronic block copolymers have been utilized for stabilization of various pharmaceutical dispersions, such as water-in-oil and oil-in-water emulsions [96,97] as well as Pluronic-based core-shell nanoparticles [98]. Pluronic-based polymeric micelles have been used for delivery of solubilized drugs and were first in class polymeric micelle drugs that underwent clinical trials [99]. Recent work also indicates that simple coating drug-encapsulated nanoparticles with certain poloxamers can significantly increase drug accumulation in the brain [100-102]. Interestingly, according to Frank Davis the idea of PEGylation actually originated from Pluronic block copolymers [71]. He had chosen PEG, rather than any other hydrophilic polymer for protein modification, because he found that a structurally related Pluronic was already in use by physicians. At that time, Pluronic was infused to patient blood to prevent the formation of lipid embolisms during the course of vessel surgery.

Perhaps, the first protein-Pluronic covalent conjugates described were insulin and antibodies attached to Pluronic analogs, which were used as targeting moieties for the delivery polymeric micelles to the brain [103]. Pluronic P85 is an amphiphilic block copolymer with a molecular mass of ca. 4600 Da having approximately equal by mass content of PPO and PEO chains. The unconjugated Pluronic P85 was formulated with a neuroleptic drug, haloperidol in the form of polymeric micelles and then blended either with Pluronic P85 modified insulin or antibodies. As a result, the protein molecules incorporated into the PEO shell of the polymeric micelles while the solubilized drug remained in the micelle core formed by PPO chains. The antibodies used in this study included either brain specific antibodies against alpha-2-glycoprotein (a2-GP) or brain non-specific antibodies against alcohol dehydrogenase (ADG). The micelles were intraperitoneally administered into mice, and the haloperidol biological activity was determined. Notably, all haloperidol micelle formulations exhibited better central response than the haloperidol alone. Among the micelle groups, the most pronounced increase of haloperidol action was observed with the micelles linked to the brain specific antibody, followed by the micelles linked to insulin, and then non-specific antibody or untargeted micelles. Further studies using a similar micelle system 
but incorporating fluorescence dye confirmed that the dye was in fact delivered to the brain parenchyma [104].

More studies then followed to understand how Pluronic block copolymers interacted with the BBB. Interestingly, selected copolymers such as Pluronic P85 were identified as potent inhibitors of P-glycoprotein (Pgp), a multidrug efflux transporter expressed in the brain endothelium [105]. Therefore, exposure to these copolymers increased permeability of Pgp substrates across the BMEC and enhanced entry of Pgp-substrates into the brain [106-108]. Moreover, fluorescently labeled Pluronic P85 and some other copolymers administered intraperitoneally in mice were shown to localize in the brain tissues $[109,110]$. The ${ }^{3} \mathrm{H}$ labeled Pluronic P85 following intravenous injection in mice was quantified in the brain, albeit at less than $1 \%$ of inj/g $[109,110]$. The mechanism of the cellular entry of Pluronic P85 has been elucidated, suggesting that the copolymer single chains co-localize with caveolin 1 and enter cells through a clathrin-independent but caveolae-dependent pathway [111]. A more recent study further demonstrated that BMEC and primary neurons take up Pluronic P85 in a fashion reminiscent of the bacterial pathogen, Cholera toxin B trafficking [112]. Although in BMEC the caveolae served as a primary entry site for the copolymer single chains, in the primary neurons devoid of caveolae, the copolymer was exploiting caveolae- and clathrin-independent routes: the uptake started from accumulation of Pluronic P85 in the cell body and was followed by anterograde trafficking of polymer towards axons/ dendrites endings. The similarity of the copolymer's trafficking with that of biological pathogens was reinforced since both bypassed early endosomes/lysosomes and transported to the endoplasmic reticulum. The copolymer finally reached the mitochondria that served as its final destination.

Parallel to these studies of single copolymer chains trafficking, Pluronic P85 was directly attached to proteins with the goal to increase protein delivery to the brain [13,31,90-92] (Table 3). Initially, the BBB impermeable enzyme, HRP, was used as a model protein [31]. The copolymer was attached to the protein amino groups through either degradable (containing disulfide bond) or non-degradable linkers. The in vitro study of the transport of the HRP conjugates across the BBMEC monolayers revealed that while all types of the conjugates displayed increased permeability compared to the unmodified protein, the conjugates with the disulfide bonds were the most efficacious. Hence, such conjugates were further selected for the PK studies in vivo. In these studies the brain delivery of the radioactively labeled unmodified and Pluronic-conjugated HRP was evaluated after their intravenous administration to mice by determining the brain/ serum ratios. The analysis of the PK of the modified HRP did not reveal any significant increase in the serum half-life compared to the native enzyme (possibly because HRP itself is already a highly stable and long-circulating protein). However, as a result of the modification the influx rate of HRP at the BBB was increased by 4-fold, which led to an improved brain uptake of the protein over time (1.8-fold increase at $200 \mathrm{~min}$ following injection). At the same time the modification did not change the volume of distribution of HRP, suggesting that the tissue sequestration of the conjugate was minimal. This indicates that such modification approach may result in an improvement in protein delivery compared to the protein fatty acid acylation, which in the case of HRP increased the volume distribution. The capillary depletion study further 
revealed that the majority of Pluronic modified HRP transported in the brain parenchyma rather than remained entrapped in the brain capillary [31]. Therefore, Pluronic modification enabled a BBB impermeable protein to enter the brain, albeit the influx rate and brain uptake of the modified HRP was less than that commonly observed for proteins that enter the brain through a BBB transporter. Further studies using BBMEC monolayers established a relationship between the structure of the block copolymer and the cell membrane binding and transport capability of the modified HRP [90]. The protein was conjugated to the copolymers that differ in the molecular mass and hydrophobicity (Pluronic L81, Pluronic P85, Pluronic L121, and Pluronic P123). Albeit the conjugation chemistry was the same as in the previous study the modification of the amino groups resulted in fairly heterogeneous products. Unfortunately, the post-modification purification, such as ion exchange chromatography, could not isolate HRP linked to a single polymer chain from the remaining species. Comparisons were then made for HRP conjugates with the average modification degrees ranging from 1 to 3 . Nevertheless, the study concluded that Pluronic P123, the copolymer having long PPO and PEO chains was the least effective in improving the HRP binding and transport in the cells. Although HRP modifications with the remaining three copolymers all enhanced the protein binding to the cells, the permeabilities of the modified proteins in the BBMEC monolayer were quite different. The greatest improvement in the transport across the BBMEC monolyaers was observed in the case of HRP modified with Pluronic L81, followed by Pluronic L121 and then Pluronic P85. Thus, it appears that the copolymers with the shortest PEO blocks (Pluronic L81 and Pluronic L121) are more favorable in terms of cell transport of the modified protein compared to the copolymer with the relatively longer PEO block (Pluronic P85) [13,90].

Based on these findings we further focused on the delivery of an antioxidant enzyme, superoxide dismutase 1 (SOD1), which can exert therapeutic effect in the brain by scavenging superoxide ions. There is a considerable body of evidence that blocking angiotensin II (AngII) central signaling, in particular by attenuating the AngII-induced increase in superoxide in the CNS could be beneficial for treatment of neurocardiovascular diseases, such as hypertension and heart failure [113-118]. However, delivery of antioxidant enzymes, such as SOD1 to central neurons is hindered by two barriers - the BBB and the neuronal cell membrane, and may be further complicated by poor serum bioavailability of the native protein. Since modification of SOD1 with the linkers containing a disulfide bond led to the enzyme inactivation, we modified SOD1 with Pluronic L81 and Pluronic P85 using a non-degradable linker [91]. In this case the protein conjugates modified by only one polymer chain were isolated by size exclusion chromatography. An AngII sensitive neuronal cell model was used to evaluate the intracellular delivery and efficacy of the resulting conjugates [91]. Of the two modified SOD1 forms the protein modified with Pluronic L81 exhibited more efficacious transport into the cells than the protein modified with Pluronic P85. A PEGyalted form of SOD1 also included in these studies did not show increased neuronal uptake compared to the unmodified enzyme. The in vivo activity of SOD1 modified with Pluronic P85 was evaluated by recording the AngII-evoked pressor response in a normal rabbit model [90]. After a single intracarotid injection the modified SOD1 attenuated the AngII-induced increase in arterial pressure for as long as day 1, 2, 3 and up to day 7; whereas no reduction in the pressor response was observed in rabbits administered 
with the native SOD1 by the same route and dose. In the heart failure rabbit model, our preliminary data also showed that intracarotid injection of the modified SOD1 led to a significant attenuation of AngII-induced response at day 3, which lasted up to day 7; whereas the inhibition of the pressor response in the native SOD1 treated group was minimal.

Another therapeutic protein that was modified by Pluronic block copolymers is leptin, a 16 $\mathrm{kDa}$ gut-brain hormone that exerts its anti-obesity activity exclusively within the brain. Although endogenous leptin is rapidly transported across the BBB by way of a specific, saturable transport system [119], systemic delivery of leptin to the brain for obesity treatment was not successful because of the poor bioavailability of leptin itself and the defect of its transport system that occurs in obesity [120-122]. We, therefore, proposed to modify leptin with Pluronic in an attempt to overcome the transport deficiency and improve leptin systemic delivery. Modification of leptin by Pluronic P85 was similar to that of SOD1 except that a biodegradable disulfide linker was used to bridge leptin and the copolymer. We have speculated that such a leptin conjugate with cleavable disulfide bonds might act as a prodrug that preserves similar serum stability as the conjugate containing the stable linker but performs better within the brain since it can activate its receptor after releasing free leptin. The first generation of Pluronic P85-modified leptin (leptin-P85) was produced using native mouse recombinant leptin and purified using the same procedure as for SOD1 conjugates [92]. Unfortunately, the purification failed to separate unmodified and modified leptin because of the interference of unreacted dimer form of leptin that eluted at the almost same time as the modified leptin. Therefore, our initial work focused on this fairly heterogeneous leptin-P85 conjugate and studied its brain PK and in vivo biological activity [92]. This modified leptin circulated 3 times longer than the native leptin and was transported across the BBB at a similar rate as the native leptin. Importantly, the BBB transport of the iodinated leptin-P85 conjugate was not inhibited by excess of unlabeled leptin or unlabeled conjugate, which suggests that this conjugate is transported to the brain through a non-saturable and leptin-transporter independent mechanism. The capillary depletion studies further confirmed that the majority of leptin-P85 accumulated in the brain parenchyma. Tissue distribution studies discovered that other than brain, modification also increased leptin uptake in heart, muscle and stomach but not in liver, lung and kidney.

The in vivo activity of the leptin-P85 conjugate was evaluated by measuring the acute feeding response in normal body weight mice. Both leptin-P85 and native leptin inhibited food intake of CD-1 mice following intracerebral ventricular administration. However, the minimum effective dose for leptin-P85 was 4- to 8-fold higher than that of the leptin. The food intake was significantly reduced after intravenous administration of leptin-P85 [92]. Moreover, our on-going studies showed that this leptin-P85 conjugate was also effective in reducing the food intake and decreasing the body weight in ob/ob mice and diet-induced obese mice. We also established a method to optimize this leptin-P85 conjugate with aiming to reduce the heterogeneity and improve the binding activity. Currently we are able to obtain more homogenous leptin-P85 conjugates. Depending on the modification degree, leptin attached by a single Pluronic P85 chain and leptin attached by multiple P85 chains enter the brain using different mechanisms but both show longer circulation times compared to the 
native leptin. These two conjugates are transported across the BBB at much lower rates than the native leptin but still significantly faster than albumin [123]. Altogether, these results indicate that Pluronic modification indeed enables leptin to enter the brain and improves leptin serum bioavailability. However, only conjugates containing multiple copolymer chains show a capability to overcome leptin transporter deficiency and enter the brain in a manner independent of the leptin BBB transporter.

As of today brain PK data suggest us that the modification of proteins with the Pluronic copolymers, on the one hand acts similarly to PEGylation, being able to improve the protein circulation time and stability, and on the other hand, can facilitate the delivery of the modified proteins across the biological barriers. The transport of Pluronic modified proteins in the BBB most likely does not involve an active transport mechanism. Pluronic P85 alone did not show any specific transporter binding capability at the luminal side of the BBB [124]. Moreover, the leakage of the conjugates through disruption of the tight junctions in BMEC should be excluded because the BBB remained intact in vitro (as follows from the parallel studies of the permeability of a paracellular marker, ${ }^{3} \mathrm{H}$ mannitol) [90], as well as in vivo (as is clear from the simultaneous measurements of the brain uptake of co-injected iodinated albumin) [92]. Quite to the contrary, the observed influx rates of the modified proteins and the evidence of their non-saturable brain uptake strongly support a diffusionbased mechanism for their transport. Interestingly, the brain transport rate of both native leptin and leptin-P85 is 2- to 3-fold higher in mice with perfusion than that of the mice without perfusion [125]. This suggests that serum attenuates the transport of the native protein and conjugate across the BBB. However, ${ }^{3} \mathrm{H}$-labeled $\mathrm{P} 85$ did not interact with any serum protein [126]. Therefore it is unlikely that serum contributes to the transport of the Pluronic modified protein in the BBB by interacting with the copolymer chains.

The data on the mechanisms of the cellular trafficking of Pluronic P85 alone, makes it tempting to suggest that similar mechanisms are also realized in the case of the Pluronic modified proteins, which could utilize the caveolae-mediated endocytosis or caveolae- and clathrin-independent pathway [111]. Our unpublished data suggest that in MDCK cells SOD1 co-localizes with transferrin and to a notably lesser amount with Cholera toxin B. In contrast, the SOD Pluronic P85 conjugate co-localizes equally with both endocytosis markers. Hence modification of SOD1 with Pluronic may shift this protein from the clarthrin pathway towards the caveolae pathway. This is further reinforced by an increased colocalization of the conjugate with caveolin-1. Future studies must further tackle the transport mechanisms of Pluronic modified proteins across the BBB. These mechanisms could be quite complex and depending on the type of the protein may include receptor mediated endocytosis, as well as lipid rafts (Figure 2). Various lipid rafts have been identified in brain the endothelium and they are believed to regulate tight junction function, transporter activity and endothelial cell adhesion [127]. Lipid-enriched membrane microdomain compartmentalization at the luminal side of the BBB allows for the apicobasal polarity [128]. Whether any of such lipid rafts are involved in binding and trafficking of Pluronic modified proteins in BBB is an important question to be addressed in the future. Such future studies could also provide a rationale for the design of novel and improved conjugates of proteins with amphiphilic block copolymer for CNS delivery. 


\section{Proteins modified with amphiphilic poly(2-oxazoline)- based block copolymers}

Poly(2-oxazoline)s (POx) is a prominent member of pseudo-polypeptides that can be synthesized by living cationic ring-opening polymerization of 2-oxazoline monomers. The well-defined structure and narrow polydispersity of POx polymers along with their low toxicity make them an attractive material for various biomedical applications. Most of the early studies using these polymers in therapeutics and drug delivery applications focused on hydrophilic homopolymers poly(2-methyl-2-oxazoline) (PMeOx) and poly(2-ethyl-2oxazoline) (PEtOx). Similar to PEG such hydrophilic POx polymers once grafted to nanoparticles or conjugated to biomacromolecules confer stealth behavior and biocompatibility. Specifically, modification of proteins with water-soluble POx was shown to improve protein stability and peripheral PK $[129,130]$. POx conjugation technologies have reached the clinical evaluation stage. Thus a small molecule drug, rotigotine conjugated to POx polymer displayed significant therapeutic response in pre-clinical Parkinson disease model and due to a long circulation the conjugate is being developed as once a week administration to treat Parkinson patient [131].

Helmut Ringsdorf who suggested to one of us that we could collaborate with Robert Luxenhofer and Rainer Jordan precipitated our interest in POx chemistry [132]. The collaboration initially focused on polymeric micelles formed by amphipiplic copolymers containing hydrophilic PMeOx or PEtOx block and hydrophobic, for example, poly(2butyl-2-oxazoline) (PBuOx) block (Table 3B). Such micelles have been shown to display unprecedented high capacity for solubilization of very poorly soluble drugs and drug blends $[132,133]$. Consequently, such micelles emerged as a powerful platform for drug delivery.

Parallel studies explored the cellular uptake of such POx based block copolymers [134] and some of these experiments revealed that similar to Pluronic P85, selected POx-based block copolymers co-localized in the cells with the Cholera toxin B. Based on that we hypothesized that these block copolymers may employ a lipid-raft mediated mechanism for the cell entry and pretty much like Pluronic block copolymers can carry proteins inside of the cells. This inspired us to dedicate effort to the development of POx-protein conjugates for brain targeting $[133,134]$ (Table 3). Conjugation of POx block copolymers to proteins followed the general procedure used to produce the protein-Pluronic conjugates, except that generation of terminal mono-amine functionalities in the copolymers was conveniently realized by terminating POx polymerization with piperazine. As in the previous cases initial work used HRP as a model protein. The studies in two cell lines, MDCK and Caco-2, revealed that modification of HRP with amphiphilic di-block copolymers, poly(MeOx-b$\mathrm{BuOx})$ and poly(EtOx-b-BuOx), has greatly increased the cellular uptake of the protein compared to unmodified HRP [93]. Interestingly, the modification of HRP with the random copolymer, poly(EtOx-co-BuOx) had little if any effect on the internalization, while hydrophilic homopolymer PMeOx clearly inhibited the cellular uptake compared to unmodified HRP.

Based on these findings the two amphiphilic di-block copolymers were selected to modify SOD1 [94]. The conjugates were purified by size exclusion chromatography yielding SOD1 
attached by 2-3 polymers and retaining 30-50\% activity. Interestingly, SOD1 modified with poly (EtOx- $b$-BuOx) exhibited higher uptake in CATH.a neurons than that of SOD1 modified with poly(MeOx- $b$-BuOx). Similar to Pluronic modified SOD1, SOD1poly $(\mathrm{EtOx}-b-\mathrm{BuOx})$ conjugate penetrated the neuronal cell membrane in an active form, as demonstrated by the inhibition of AngII-induced increase in intracellular superoxide. The SOD1-poly(EtOx- $b$-BuOx) mainly utilized lipid raft/caveolae mediated endocytosis to internalize into CATH.a neurons, which was similar to the internalization of the copolymer alone. The trafficking itinerary of this conjugate included its accumulation in endoplasmic reticulum and mitochondria [94].

The in vivo brain $\mathrm{PK}$ study demonstrated that poly(EtOx- $b$-BuOx) modification enabled otherwise BBB impermeable SOD1 to cross the BBB and elongated the protein serum circulation time by 2 -fold. The transport appeared to be non-saturable and the majority of the transported protein was in the brain parenchyma. The influx rate was greater than that of albumin, albeit notably less than that of substances that employ active transport systems to cross the BBB. The improvement in the brain penetration and serum circulation of SOD1poly(EtOx- $b$-BuOx) were similar to those that were observed with Pluronic P85 modified HRP, suggesting that both copolymers may play a similar role in CNS delivery [31,94]. However, due to its purity, narrow size distribution and stability POx may be superior as an agent for protein modification compared to Pluronic. Albeit detailed discussion of the versatile synthetic POx platform is beyond the scope of this review [132], we would like to point out that the living cationic ring-opening polymerization of 2-oxazolines can produce well-defined amphiphilic POx. For example, poly(EtOx- $b$-BuOx) used in the above studies was synthesized by sequential block copolymerization of EtOx with $\mathrm{BuOx}$, resulting a polydispersity index of 1.09. In contrast, as a chemical product, Pluronic block copolymers are relatively polydisperse and often contain considerable admixtures of a diblock copolymer. Synthesis of Pluronic starts from polymerization of propylene oxide in the presence of alkaline catalysis to generate a bifuntional PPO macroinitiator followed by adding ethylene oxide to form symmetric PEO blocks [135]. The reaction conditions and copolymer manufacturing are well established and are fairly inexpensive. However in commercial synthesis procedure a side reaction also occurs and thereby generates allylattached PPO-PEO. Our unpublished mass spectra and NMR data revealed the presence of diblocks in commercial samples of Pluronics. Following purifications used in the generation of mono-amine Pluronic derivatives, most of the diblocks can be removed, albeit careful elution and precise characterization of the collected fractions are required. Occasionally the residual mono-amine di-block copolymers are generated that can attach to proteins in a subsequent conjugation step, attributing to the heterogeneity of the final product. Thus, refining the chemistry would be needed to produce more structurally defined Pluronicprotein conjugates, while in case of the Pox-based conjugates, the synthesis may be less challenging.

\section{Conclusions}

Modification of proteins with hydrophobic moieties enhances protein interactions with physiological membranes and protein uptake in cells. Both fatty acylation proteins and conjugation of proteins with amphiphilic block copolymers can increase protein residence in 
peripheral circulation and permeability at the BBB. Although the underlying mechanisms for these phenomena may differ and are still under investigation, preclinical brain PK and efficacy studies strongly support the benefits of both strategies and their potential for improved brain delivery of various proteins. The case in point, a fatty acylated GLP-1 has been successfully tested in Phase III clinical trials for the treatment of obesity. This has stimulated further studies on fatty acylation of the gut-brain hormones. Selected Pluronic block copolymers are widely used in pharmaceutical industry as excipients. Likewise POx polymers appear to be relatively safe and soon will reach clinical evaluation stage. Modification of several proteins with these polymers has resulted in improved blood circulation and CNS delivery. One should expect that these protein modification technologies and products will also advance the clinics.

\section{Acknowledgments}

We greatly appreciate the continuous support and advice from Dr William A. Banks and his specific comments during the manuscript preparation.

\section{References}

1. Brasnjevic I, Steinbusch HW, Schmitz C, Martinez-Martinez P. Delivery of peptide and protein drugs over the blood-brain barrier. Prog Neurobiol. 2009; 87:212-51. [PubMed: 19395337]

2. Boer AG, Gaillard PJ. Drug targeting to the brain. Ann Rev Pharmacol Toxicol. 2007; 47:323-55. [PubMed: 16961459]

3. Gabathuler R. Approaches to transport therapeutic drugs across the blood-brain barrier to treat brain diseases. Neurobiol Dis. 2010; 37:48-57. [PubMed: 19664710]

4. Lichota J, Skjorringe T, Thomsen LB, Moos T. Macromolecular drug transport into the brain using targeted therapy. J Neurochem. 2010; 113:1-13. [PubMed: 20015155]

5. Thorne RG, Frey WH II. Delivery of neurotrophic factors to the central nervous system: pharmacokinetic considerations. Clin Pharmacokinetics. 2001; 40:907-46.

6. Dhuria SV, Hanson LR, Frey WH II. Intranasal delivery to the central nervous system: mechanisms and experimental considerations. J Pharm Sci. 2010; 99:1654-73. [PubMed: 19877171]

7. Landis MS, Boyden T, Pegg S. Nasal-to-cns drug delivery: where are we now and where are we heading? An industrial perspective. Ther Deliv. 2012; 3:195-208. [PubMed: 22834197]

8. Lochhead JJ, Thorne RG. Intranasal delivery of biologics to the central nervous system. Adv Drug Deliv Rev. 2012; 64:614-28. [PubMed: 22119441]

9. Merkus FW, van den Berg MP. Can nasal drug delivery bypass the blood-brain barrier? Questioning the direct transport theory. Drugs R\&D. 2007; 8:133-44.

10. Watts RJ, Dennis MS. Bispecific antibodies for delivery into the brain. Curr Opin Chem Biol. 2013; 17:393-9. [PubMed: 23570979]

11. Yu YJ, Zhang Y, Kenrick M, et al. Boosting brain uptake of a therapeutic antibody by reducing its affinity for a transcytosis target. Sci Translational Med. 2011; 84:44-51.

12. Andrieux K, Couvreur P. Polyalkylcyanoacrylate nanoparticles for delivery of drugs across the blood-brain barrier. Wiley interdisciplinary reviews. Nanomed Nanobiotechnol. 2009; 1:463-74

13. Gilmore JL, Yi X, Quan L, Kabanov AV. Novel nanomaterials for clinical neuroscience. J Neuroimmune Pharmacol. 2008; 3:83-94. [PubMed: 18210200]

14. Kabanov AV, Gendelman HE. Nanomedicine in the diagnosis and therapy of neurodegenerative disorders. Prog Polymer Sci. 2007; 32:1054-82.

15. Tiwari SB, Amiji MM. A review of nanocarrier-based cns delivery systems. Curr Drug Deliv. 2006; 3:219-32. [PubMed: 16611008] 
16. Tosi G, Costantino L, Rivasi F, et al. Targeting the central nervous system: in vivo experiments with peptide-derivatized nanoparticles loaded with loperamide and rhodamine-123. J Control Release. 2007; 122:1-9. [PubMed: 17651855]

17. Tosi G, Vergoni AV, Ruozi B, et al. Sialic acid and glycopeptides conjugated plga nanoparticles for central nervous system targeting: In vivo pharmacological evidence and biodistribution. J Control Release. 2010; 145:49-57. [PubMed: 20338201]

18. Tosi G, Bortot B, Ruozi B, et al. Potential use of polymeric nanoparticles for drug delivery across the blood-brain barrier. Curr Med Chem. 2013; 20:2212-25. [PubMed: 23458620]

19. Townsend SA, Evrony GD, Gu FX, et al. Tetanus toxin c fragment-conjugated nanoparticles for targeted drug delivery to neurons. Biomaterials. 2007; 28:5176-84. [PubMed: 17854886]

20. Vergoni AV, Tosi G, Tacchi R, et al. Nanoparticles as drug delivery agents specific for cns: In vivo biodistribution. Nanomedicine. 2009; 5:369-77. [PubMed: 19341816]

21. Magee T, Seabra MC. Fatty acylation and prenylation of proteins: what's hot in fat. Curr Opinion Cell Biol. 2005; 17:190-6. [PubMed: 15780596]

22. Nadolski MJ, Linder ME. Protein lipidation. FEBS J. 2007; 274:5202-10. [PubMed: 17892486]

23. Resh MD. Trafficking and signaling by fatty-acylated and prenylated proteins. Nat Chem Biol. 2006; 2:584-90. [PubMed: 17051234]

24. Smotrys JE, Linder ME. Palmitoylation of intracellular signaling proteins: regulation and function. Ann Rev Biochem. 2004; 73:559-87. [PubMed: 15189153]

25. Torchilin VP, Klibanov AL. Immobilization of proteins on liposome surface. Enzyme Microb Technol. 1981; 3:297-304.

26. Chekhonin VP, Kabanov AV, Zhirkov YA, Morozov GV. Fatty acid acylated fab-fragments of antibodies to neurospecific proteins as carriers for neuroleptic targeted delivery in brain. FEBS Lett. 1991; 287:149-52. [PubMed: 1715283]

27. Kabanov AV, Levashov AV, Martinek K. Transformation of water-soluble enzymes into membrane active form by chemical modification. Annals N Y Acad Sci. 1987; 501:63-6.

28. Kabanov AV, Levashov AV, Alakhov V. Lipid modification of proteins and their membrane transport. Protein Eng. 1989; 3:39-42. [PubMed: 2682609]

29. Slepnev VI, Phalente L, Labrousse H, et al. Fatty acid acylated peroxidase as a model for the study of interactions of hydrophobically- modified proteins with mammalian cells. Bioconjug Chem. 1995; 6:608-15. [PubMed: 8974461]

30. Chopineau J, Robert S, Fenart L, et al. Monoacylation of ribonuclease a enables its transport across an in vitro model of the blood-brain barrier. J Control Release. 1998; 56:231-7. [PubMed: 9801446]

31. Batrakova EV, Vinogradov SV, Robinson SM, et al. Polypeptide point modifications with fatty acid and amphiphilic block copolymers for enhanced brain delivery. Bioconjug Chem. 2005; 16:793-802. [PubMed: 16029020]

32. Lasarev, AP.; Sukharev, OI.; Gruzdev, KN., et al. Bioactive preparation for pigs, method of its preparing, method of prophylaxis and treatment of viral disease in pigs. 1996. RU 2058789 C1. Russian

33. Levashov AV, Kabanov AV, Khmelnitskii Yu L, et al. Chemical modification of proteins (enzymes) by water-insoluble reagents. Doklady Akademii Nauk SSSR. 1984; 278:246-8. [PubMed: 6489129]

34. Severin ES, Melik-Nubarov NS, Ovcharenko AV, et al. Hydrophobized antiviral antibodies and antisense oligonucleotides. Adv Enzyme Regul. 1991; 31:417-30. [PubMed: 1877397]

35. Kabanov, A. Soviet Scientific Reviews Series, Section D. Switzerland: Taylor \& Francis Group; 1992. Enhancement of macromolecule penetration into cells and nontraditional drug delivery systems.

36. Alakhov V, Kabanov AV, Batrakova EV, et al. Increasing cytostatic effects of ricin a chain and staphylococcus aureus enterotoxin a through in vitro hydrophobization with fatty acid residues. Biotechnol Appl Biochem. 1990; 12:94-8. [PubMed: 2310510]

37. Kabanov AV, Ovcharenko AV, Melik-Hubarov NS, et al. Fatty acid acylated antibodies against virus suppress its reproduction in cells. FEBS Lett. 1989; 250:238-40. [PubMed: 2753133] 
38. Yuan L, Wang J, Shen WC. Lipidization of human interferon-alpha: a new approach toward improving the delivery of protein drugs. J Control Release. 2008; 129:11-17. [PubMed: 18448186]

39. Bellmann-Sickert K, Elling CE, Madsen AN, et al. Long-acting lipidated analogue of human pancreatic polypeptide is slowly released into circulation. J Med Chem. 2011; 54:2658-67. [PubMed: 21410292]

40. Banks WA, Tschop M, Robinson SM, Heiman ML. Extent and direction of ghrelin transport across the blood-brain barrier is determined by its unique primary structure. J Pharmacol Exp Ther. 2002; 302:822-7. [PubMed: 12130749]

41. Bednarek MA, Feighner SD, Pong SS, et al. Structure-function studies on the new growth hormone-releasing peptide, ghrelin: minimal sequence of ghrelin necessary for activation of growth hormone secretagogue receptor 1a. J Med Chem. 2000; 43:4370-6. [PubMed: 11087562]

42. Chen CY, Fujimiya M, Asakawa A, et al. At the cutting edge: Ghrelin gene products in food intake and gut motility. Neuroendocrinology. 2009; 89:9-17. [PubMed: 18931475]

43. Horvath TL, Diano S, Sotonyi P, et al. Minireview: ghrelin and the regulation of energy balance a hypothalamic perspective. Endocrinology. 2001; 142:4163-9. [PubMed: 11564668]

44. Kojima M, Hosoda H, Date Y, et al. Ghrelin is a growth-hormone-releasing acylated peptide from stomach. Nature. 1999; 402:656-60. [PubMed: 10604470]

45. Garber AJ. Long-acting glucagon-like peptide 1 receptor agonists: a review of their efficacy and tolerability. Diabetes Care. 2011; 34:S279-84. [PubMed: 21525469]

46. Jespersen MJ, Knop FK, Christensen M. Glp-1 agonists for type 2 diabetes: pharmacokinetic and toxicological considerations. Expert Opin Drug Metab Toxicol. 2013; 9:17-29. [PubMed: 23094590]

47. Kanoski SE, Fortin SM, Arnold M, et al. Peripheral and central glp-1 receptor populations mediate the anorectic effects of peripherally administered glp-1 receptor agonists, liraglutide and exendin-4. Endocrinology. 2011; 152:3103-12. [PubMed: 21693680]

48. Conde-Frieboes $\mathrm{K}$, Thogersen $\mathrm{H}$, Lau JF, et al. Identification and in vivo and in vitro characterization of long acting and melanocortin 4 receptor (mc4-r) selective alpha-melanocytestimulating hormone (alpha-msh) analogues. J Med Chem. 2012; 55:1969-77. [PubMed: 22335602]

49. Wulff, BS. Safety and efficacy of a long-acting alpha-msh analogue, mc4-nn2-0453, in overweight to obese but otherwise healthy subjects. Keystone Symposia on Molecular and Cellular Biology, Neuronal Control of Appetite, Metabolism and Weight; 2013; Fairmont Banff Springs, Banff, Alberta, Canada.

50. Sanger GJ, Lee K. Hormones of the gut-brain axis as targets for the treatment of upper gastrointestinal disorders. Nat Rev Drug Discov. 2008; 7:241-54. [PubMed: 18309313]

51. Barsh GS, Schwartz MW. Genetic approaches to studying energy balance: perception and integration. Nat Rev Genet. 2002; 3:589-600. [PubMed: 12154382]

52. Boughton CK, Murphy KG. Can neuropeptides treat obesity? A review of neuropeptides and their potential role in the treatment of obesity. Brit J Pharmacol. 2012 [Epub ahead of print]. 10.1111/ bph. 12037

53. McGavigan AK, Murphy KG. Gut hormones: the future of obesity treatment? Brit J Clin Pharmacol. 2012; 74:911-19. [PubMed: 22452339]

54. Vasselli JR, Scarpace PJ, Harris RB, Banks WA. Dietary components in the development of leptin resistance. Adv Nutr. 2013; 4:164-75. [PubMed: 23493533]

55. Colon-Gonzalez F, Kim GW, Lin JE, et al. Obesity pharmacotherapy: what is next? Mol Aspects Med. 2013; 34:71-83. [PubMed: 23103610]

56. Hofbauer KG, Nicholson JR, Boss O. The obesity epidemic: current and future pharmacological treatments. Ann Rev Pharmacol Toxicol. 2007; 47:565-92. [PubMed: 17002599]

57. Holst JJ. The physiology of glucagon-like peptide 1. Physiological Rev. 2007; 87:1409-39.

58. Maletinska, L.; Nagelova, V.; Ticha, A., et al. Lipidated analogs of prolactin-releasing peptide decrease food intake after peripheral administration. Keystone Symposia on Molecular and Cellular Biology, Neuronal Control of Appetite, Metabolism and Weight; 2012; Fairmont Banff Springs, Banff, Alberta, Canada. 
59. Edmond J, Higa TA, Korsak RA, et al. Fatty acid transport and utilization for the developing brain. J Neurochem. 1998; 70:1227-34. [PubMed: 9489745]

60. Edmond J. Essential polyunsaturated fatty acids and the barrier to the brain: the components of a model for transport. J Mol Neurosci. 2001; 16:181-93. discussion 215-21. [PubMed: 11478373]

61. Vangaveti V, Shashidhar V, Jarrod G, et al. Free fatty acid receptors: emerging targets for treatment of diabetes and its complications. Ther Adv Endocrinol Metabol. 2010; 1:165-75.

62. Ma D, Lu L, Boneva NB, et al. Expression of free fatty acid receptor gpr40 in the neurogenic niche of adult monkey hippocampus. Hippocampus. 2008; 18:326-33. [PubMed: 18064707]

63. Pisal DS, Kosloski MP, Balu-Iyer SV. Delivery of therapeutic proteins. J Pharm Sci. 2010; 99:2557-75. [PubMed: 20049941]

64. Duncan R, Gilbert HR, Carbajo RJ, Vicent MJ. Polymer masked-unmasked protein therapy. 1. Bioresponsive dextrin-trypsin and -melanocyte stimulating hormone conjugates designed for alpha-amylase activation. Biomacromolecules. 2008; 9:1146-54. [PubMed: 18348531]

65. Ferguson EL, Duncan R. Dextrin-phospholipase a2: synthesis and evaluation as a bioresponsive anticancer conjugate. Biomacromolecules. 2009; 10:1358-64. [PubMed: 19354276]

66. Hardwicke J, Ferguson EL, Moseley R, et al. Dextrin-rhegf conjugates as bioresponsive nanomedicines for wound repair. J Control Release. 2008; 130:275-83. [PubMed: 18700156]

67. Hardwicke J, Moseley R, Stephens P, et al. Bioresponsive dextrin-rhegf conjugates: in vitro evaluation in models relevant to its proposed use as a treatment for chronic wounds. Mol Pharm. 2010; 7:699-707. [PubMed: 20166755]

68. Oh EJPK, Kim KS, Kim J, et al. Target specific and long-acting delivery of protein, peptide, and nucleotide therapeutics using hyaluronic acid derivatives. J Control Release. 2010; 141:2-12. [PubMed: 19758573]

69. Kopecek J, Kopeckova P. Hpma copolymers: Origins, early developments, present, and future. Adv Drug Deliv Rev. 2009; 62:122-49. [PubMed: 19919846]

70. Chapman AP. Pegylated antibodies and antibody fragments for improved therapy: a review. Adv Drug Deliv Rev. 2002; 54:531-45. [PubMed: 12052713]

71. Davis FF. The origin of pegnology. Adv Drug Deliv Rev. 2002; 54:457-8. [PubMed: 12052708]

72. Hinds KD, Kim SW. Effects of peg conjugation on insulin properties. Adv Drug Deliv Rev. 2002; 54:505-30. [PubMed: 12052712]

73. Kinstler O, Molineux G, Treuheit M, et al. Mono-n-terminal poly(ethylene glycol)-protein conjugates. Adv Drug Deliv Rev. 2002; 54:477-85. [PubMed: 12052710]

74. Rajender Reddy K, Modi MW, Pedder S. Use of peginterferon alfa-2a (40 kd) (pegasys) for the treatment of hepatitis c. Adv Drug Deliv Reviews. 2002; 54:571-86.

75. Roberts MJ, Bentley MD, Harris JM. Chemistry for peptide and protein pegylation. Adv Drug Deliv Rev. 2002; 54:459-76. [PubMed: 12052709]

76. Sato H. Enzymatic procedure for site-specific pegylation of proteins. Adv Drug Deliv Rev. 2002; 54:487-504. [PubMed: 12052711]

77. Veronese FM, Caliceti P, Schiavon O, Sergi M. Polyethylene glycol-superoxide dismutase, a conjugate in search of exploitation. Adv Drug Deliv Rev. 2002; 54:587-606. [PubMed: 12052716]

78. Veronese FM, Harris JM. Introduction and overview of peptide and protein pegylation. Adv Drug Deliv Rev. 2002; 54:453-6. [PubMed: 12052707]

79. Wang YS, Youngster S, Grace M, et al. Structural and biological characterization of pegylated recombinant interferon alpha-2b and its therapeutic implications. Adv Drug Deliv Rev. 2002; 54:547-70. [PubMed: 12052714]

80. Abuchowski A, McCoy JR, Palczuk NC, et al. Effect of covalent attachment of polyethylene glycol on immunogenicity and circulating life of bovine liver catalase. J Biol Chem. 1977; 252:3582-6. [PubMed: 16907]

81. Abuchowski A, van Es T, Palczuk NC, Davis FF. Alteration of immunological properties of bovine serum albumin by covalent attachment of polyethylene glycol. J Biol Chem. 1977; 252:3578-81. [PubMed: 405385] 
82. Maeda H, Ueda M, Morinaga T, Matsumoto T. Conjugation of poly(styrene-co-maleic acid) derivatives to the antitumor protein neocarzinostatin: pronounced improvements in pharmacological properties. J Med Chem. 1985; 28:455-61. [PubMed: 3156994]

83. Maeda H. Smancs and polymer-conjugated macromolecular drugs: advantages in cancer chemotherapy. Adv Drug Deliv Rev. 1991; 6:181-202.

84. Maeda HaK, T. Metamorphosis of neocarzinostatin to smancs: chemistry, biology, pharmacology, and clinical effect of the first prototype anticancer polymer therapeutic. Tokyo, Berlin, New York: Springer Verlag; 1997. p. 227-67.

85. Kunimasa JI, Itoga Y, Yasuhara M, et al. Pharmacokinetics and pharmacological effect of recombinant human granulocyte colony-stimulating factor conjugated to poly(styrene-co-maleic acid) in rats. J Pharm Pharmacol. 1999; 51:777-82. [PubMed: 10467951]

86. Mu Y, Kamada H, Kaneda Y, et al. Bioconjugation of laminin peptide yigsr with poly(styrene comaleic acid) increases its antimetastatic effect on lung metastasis of b16-bl6 melanoma cells. Biochem Biophys Res Commun. 1999; 255:75-9. [PubMed: 10082658]

87. Ogino T, Inoue M, Ando Y, et al. Chemical modification of superoxide dismutase. Extension of plasma half life of the enzyme through its reversible binding to the circulating albumin. Int $\mathbf{J}$ Peptide Protein Res. 1988; 32:153-9. [PubMed: 3220661]

88. Kobayashi A, Oda T, Maeda H. Protein binding of macromolecular anticancer agent smancs: characterization of poly(styrene-co-maleic acid) derivatives as an albumin binding ligand. $\mathrm{J}$ Bioactive Compatible Polymers. 1988; 3:319-33.

89. Yi X, Batrakova E, Banks WA, et al. Protein conjugation with amphiphilic block copolymers for enhanced cellular delivery. Bioconjug Chem. 2008; 19:1071-7. [PubMed: 18447367]

90. Yi, X. Protein modification by pluronic block copolymer for brain delivery [thesis]. University of Nebraska Medical Center; 2010.

91. Yi X, Zimmerman MC, Yang R, et al. Pluronic-modified superoxide dismutase 1 attenuates angiotensin ii-induced increase in intracellular superoxide in neurons. Free Radical Biol Med. 2010; 49:548-58. [PubMed: 20493251]

92. Price TO, Farr SA, Yi X, et al. Transport across the blood-brain barrier of pluronic leptin. J Pharmacol Exp Ther. 2010; 333:253-63. [PubMed: 20053933]

93. Tong J, Luxenhofer R, Yi X, et al. Protein modification with amphiphilic block copoly(2oxazoline)s as a new platform for enhanced cellular delivery. Mol Pharm. 2010; 7:984-92. [PubMed: 20550191]

94. Tong J, Yi X, Luxenhofer R, et al. Conjugates of superoxide dismutase 1 with amphiphilic poly(2oxazoline) block copolymers for enhanced brain delivery: synthesis, characterization and evaluation in vitro and in vivo. Mol Pharm. 2013; 10:360-77. [PubMed: 23163230]

95. Cellesi F. Thermoresponsive hydrogels for cellular delivery. Ther Deliv. 2012; 3:1395-407. [PubMed: 23323558]

96. Florence AT, Whitehill D. Stabilization of water/oil/water multiple emulsions by polymerization of the aqueous phases. J Pharm Pharmacol. 1982; 34:687-91. [PubMed: 6129296]

97. Forster D, Washington C, Davis SS. Toxicity of solubilized and colloidal amphotericin b formulations to human erythrocytes. J Pharm Pharmacol. 1988; 40:325-8. [PubMed: 2899626]

98. Jung YW, Lee H, Kim JY, et al. Pluronic-based core/shell nanoparticles for drug delivery and diagnosis. Curr Med Chem. 2013; 20:3488-99. [PubMed: 23745558]

99. Kabanov AV, Alakhov VY. Pluronic block copolymers in drug delivery: from micellar nanocontainers to biological response modifiers. Crit Rev Ther Drug Carrier Syst. 2002; 19:1-72. [PubMed: 12046891]

100. Chen YC, Hsieh WY, Lee WF, Zeng DT. Effects of surface modification of plga-peg-plga nanoparticles on loperamide delivery efficiency across the blood-brain barrier. J Biomater Appl. 2013; 27:909-22. [PubMed: 22207601]

101. Gelperina S, Maksimenko O, Khalansky A, et al. Drug delivery to the brain using surfactantcoated poly(lactide-co-glycolide) nanoparticles: influence of the formulation parameters. Eur J Pharm Biopharm. 2010; 74:157-63. [PubMed: 19755158] 
102. Kulkarni SA, Feng SS. Effects of surface modification on delivery efficiency of biodegradable nanoparticles across the blood-brain barrier. Nanomedicine (Lond). 2011; 6:377-94. [PubMed: 21385139]

103. Kabanov AV, Chekhonin VP, Alakhov V, et al. The neuroleptic activity of haloperidol increases after its solubilization in surfactant micelles. Micelles as microcontainers for drug targeting. FEBS Lett. 1989; 258:343-5. [PubMed: 2599097]

104. Kabanov AV, Batrakova EV, Melik-Nubarov NS, et al. A new class of drug carriers: Micelles of poly (oxyethylene)-poly (oxypropylene) block copolymers as microcontainers for drug targeting from blood in brain. J Control Release. 1992; 22:141-58.

105. Miller DW, Batrakova EV, Waltner TO, et al. Interactions of pluronic block copolymers with brain microvessel endothelial cells: evidence of two potential pathways for drug absorption. Bioconjug Chem. 1997; 8:649-57. [PubMed: 9327127]

106. Batrakova EV, Han HY, Miller DW, Kabanov AV. Effects of pluronic p85 unimers and micelles on drug permeability in polarized bbmec and caco-2 cells. Pharm Res. 1998; 15:1525-32. [PubMed: 9794493]

107. Batrakova EV, Li S, Miller DW, Kabanov AV. Pluronic p85 increases permeability of a broad spectrum of drugs in polarized bbmec and caco-2 cell monolayers. Pharm Res. 1999; 16:136672. [PubMed: 10496651]

108. Batrakova EV, Miller DW, Li S, et al. Pluronic p 85 enhances the delivery of digoxin to the brain: in vitro and in vivo studies. J Pharmacol Exp Ther. 2001; 296:551-7. [PubMed: 11160643]

109. Batrakova EV, Li S, Alakhov VY, et al. Optimal structure requirements for pluronic block copolymers in modifying p-glycoprotein drug efflux transporter activity in bovine brain microvessel endothelial cells. J Pharmacol Exp Ther. 2003; 304:845-54. [PubMed: 12538842]

110. Nametkin SN, AKLD, Kabanov AV, Levashov AV. Modulation of membrane activity of an enzyme in reversed micelle system with a change of media ph (using alkaline phosphatase as an example). Bioorganicheskaia Khimiia. 1992; 18:777-83. [PubMed: 1384508]

111. Sahay G, Batrakova EV, Kabanov AV. Different internalization pathways of polymeric micelles and unimers and their effects on vesicular transport. Bioconjug Chem. 2008; 19:2023-9. [PubMed: 18729494]

112. Sahay G, Gautam V, Luxenhofer R, Kabanov AV. The utilization of pathogen-like cellular trafficking by single chain block copolymer. Biomaterials. 2009; 31:1757-64. [PubMed: 19963266]

113. Ding Y, Li YL, Zimmerman MC, et al. Role of cuzn superoxide dismutase on carotid body function in heart failure rabbits. Cardiovasc Res. 2009; 81:678-85. [PubMed: 19091790]

114. Gao L, Wang W, Li YL, et al. Superoxide mediates sympathoexcitation in heart failure: roles of angiotensin ii and nad(p)h oxidase. Circ Res. 2004; 95:937-44. [PubMed: 15459075]

115. Gao L, Wang W, Liu D, Zucker IH. Exercise training normalizes sympathetic outflow by central antioxidant mechanisms in rabbits with pacing-induced chronic heart failure. Circulation. 2007; 115:3095-102. [PubMed: 17548725]

116. Hirooka Y. Role of reactive oxygen species in brainstem in neural mechanisms of hypertension. Auton Neurosci. 2008; 142:20-4. [PubMed: 18650132]

117. Zimmerman MC, Lazartigues E, Lang JA, et al. Superoxide mediates the actions of angiotensin ii in the central nervous system. Circulation Res. 2002; 91:1038-45. [PubMed: 12456490]

118. Zimmerman MC, Lazartigues E, Sharma RV, Davisson RL. Hypertension caused by angiotensin ii infusion involves increased superoxide production in the central nervous system. Circulation Res. 2004; 95:210-16. [PubMed: 15192025]

119. Banks WA, Kastin AJ, Huang W, et al. Leptin enters the brain by a saturable system independent of insulin. Peptides. 1996; 17:305-11. [PubMed: 8801538]

120. Levin BE, Dunn-Meynell AA, Banks WA. Obesity-prone rats have normal blood-brain barrier transport but defective central leptin signaling before obesity onset. Am J Physiol. 2004; 286:R143-50.

121. Schwartz MW, Woods SC, Porte D Jr, et al. Central nervous system control of food intake. Nature. 2000; 404:661-71. [PubMed: 10766253] 
122. Wu-Peng XS, Chua SC Jr, Okada N, et al. Phenotype of the obese koletsky (f) rat due to tyr763stop mutation in the extracellular domain of the leptin receptor (lepr): evidence for deficient plasma-to-csf transport of leptin in both the zucker and koletsky obese rat. Diabetes. 1997; 46:513-18. [PubMed: 9032111]

123. Yi, X.; Yuan, D.; Banks, WA.; Kabanov, AV. Leptin analogs overcome leptin peripheral resistance and control appetite in diet induced obese mice. Keystone Symposia on Molecular and Cellular Biology, Neuronal Control of Appetite, Metabolism and Weight; 2012; Fairmont Banff Springs, Banff, Alberta, Canada.

124. Zhang X, Alakhova DY, Batrakova EV, et al. Effect of pluronic p85 on amino acid transport in bovine brain microvessel endothelial cells. J Neuroimmune Pharmacol. 2009; 4:35-46. [PubMed: 18677571]

125. Banks WA, DiPalma CR, Farrell CL. Impaired transport of leptin across the blood-brain barrier in obesity. Peptides. 1999; 20:1341-5. [PubMed: 10612449]

126. Batrakova EV, Li S, Li Y, et al. Distribution kinetics of a micelle-forming block copolymer pluronic p85. J Control Release. 2004; 100:389-97. [PubMed: 15567504]

127. Dodelet-Devillers A, Cayrol R, van Horssen J, et al. Functions of lipid raft membrane microdomains at the blood-brain barrier. J Mol Med (Berl). 2009; 87:765-74. [PubMed: 19484210]

128. Manes S, Mira E, Gomez-Mouton C, et al. Membrane raft microdomains mediate front-rear polarity in migrating cells. EMBO J. 1999; 18:6211-20. [PubMed: 10562533]

129. Mero A, Pasut G, Dalla Via L, et al. Synthesis and characterization of poly(2-ethyl 2-oxazoline)conjugates with proteins and drugs: suitable alternatives to peg-conjugates? J Control Release. 2008; 125:87-95. [PubMed: 18031860]

130. Viegas TX, Bentley MD, Harris JM, et al. Polyoxazoline: chemistry, properties, and applications in drug delivery. Bioconjug Chem. 2011; 22:976-86. [PubMed: 21452890]

131. Moreadith, RWVT.; Standaert, DG.; Bentley, MD., et al. Ser-214, a novel polymer-conjugated rotigotine formulation affords greatly extended duration of anti-parkinsonian effect and enhanced plasma exposure following a single administration in rodents and primates. 16th International Conference of Parkinson's Disease and Movement Disorders; 2012; Dublin, Ireland.

132. Luxenhofer R, Han Y, Schulz A, et al. Poly(2-oxazoline)s as polymer therapeutics. Macromol Rapid Commun. 2012; 33:1613-31. [PubMed: 22865555]

133. Luxenhofer R, Schulz A, Roques C, et al. Doubly amphiphilic poly(2-oxazoline)s as highcapacity delivery systems for hydrophobic drugs. Biomaterials. 2010; 31:4972-9. [PubMed: 20346493]

134. Luxenhofer R, Sahay G, Schulz A, et al. Structure-property relationship in cytotoxicity and cell uptake of poly(2-oxazoline) amphiphiles. J Control. 2011; 153:73-82.

135. Schmolka I. A review of block polymer surfactants. J Amer Oil Chem Soc. 1977; 54:110-16. 

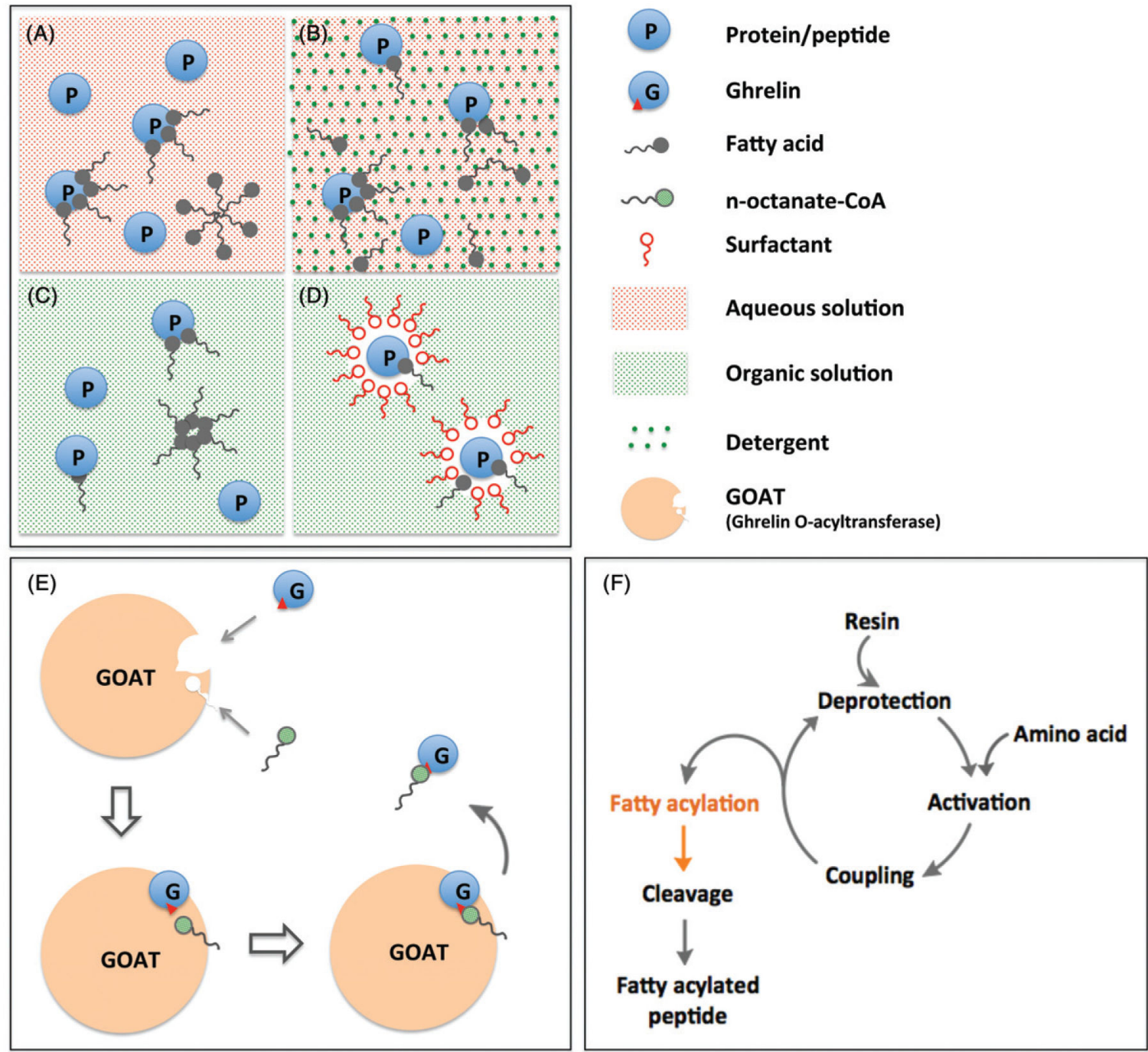

Figure 1.

Methods of protein/peptide modification by fatty acid. Chemical acylation can be achieved in either aqueous (A and B) or organic (C and D) solution. Reaction in aqueous solution in general better preserves protein activity than in organic solvent. However, fatty acids do not solubilize well in aqueous solution and the obtained products often show low yield with high heterogeneity (A). Increasing fatty acid solubility by adding detergent to the aqueous solution can result in a relatively higher yield and more homogeneous product (B). Reacting protein/peptide with fatty acid directly in organic solvent is not recommended because of protein inactivation and solubility issues (C). However, reacting protein with fatty acid using a hydrated reverse micelle system in organic solution proceeds efficiently and in most cases allows recovering more-or-less uniformly modified protein retaining relatively high activity (D). A site-specific fatty acylation can be achieved via enzymatic catalysis. Endogenous ghrelin has shown to be octanoylated specifically at the serine 3 position, a post-translation step that is catalyzed by ghrelin O-acylatransferase (GOAT) (E). Since organic solvent has 
less impact on peptide activity, fatty acylation of short sequence peptides can be done during solid phase synthesis cycle, allowing for a clean product with high yield (F). 


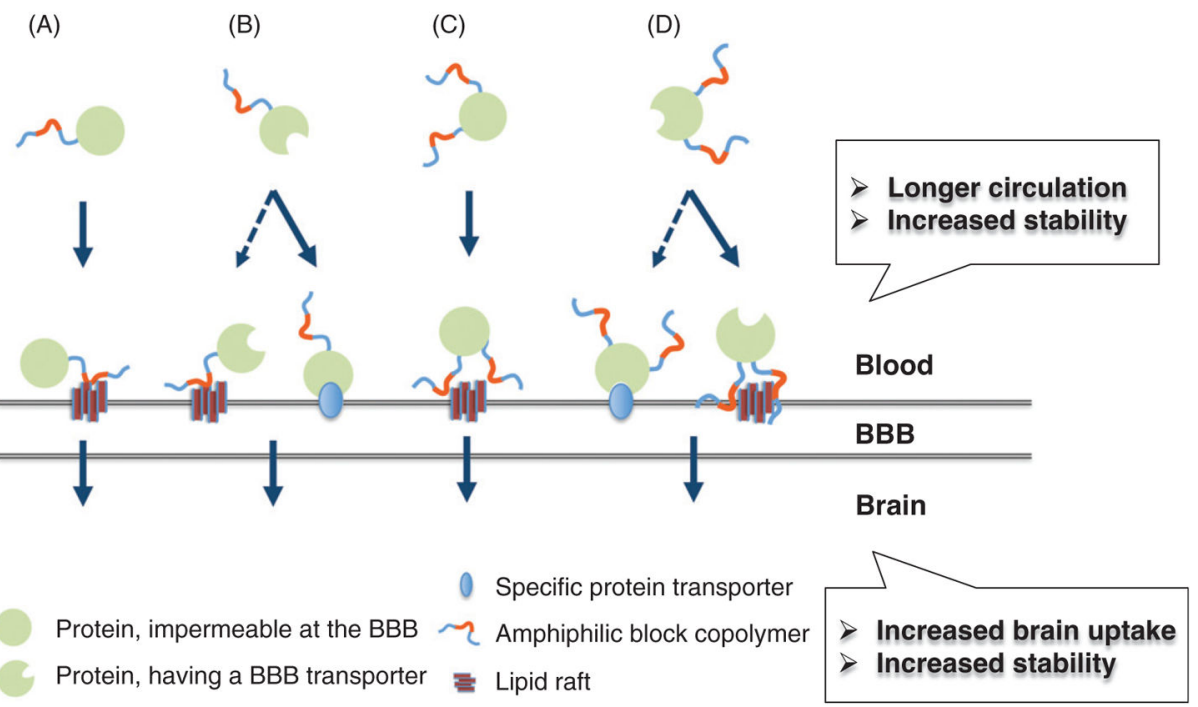

Figure 2.

Hypothetical mechanisms of the blood to brain transport of Pluronic conjugated proteins. (A) In a protein modified with a single Pluronic molecule the block copolymer hydrophobic chains (PPO) bind to lipid rafts resulting in protein transport across the BBB. (B) The protein modified with a single Pluronic molecule is capable of binding with the $\mathrm{BBB}$ transporter as well as lipid rafts in the BBB. Both mechanisms lead to the transport across the BBB albeit the protein transporter makes the greater contribution (likely case of leptinP85 with single Pluronic chain attached). (C) In a protein modified with multiple Pluronic molecules the PPO chains bind to lipid rafts resulting in protein transport across the BBB. (D) The protein modified with a multiple Pluronic molecules binds with lipid rafts, which serve as major route for the conjugate CNS entry. The binding of this protein with its transporter is either inhibited or does not result in efficient transport across the BBB (likely case of leptin-P85 with multiple Pluronic chains attached). 


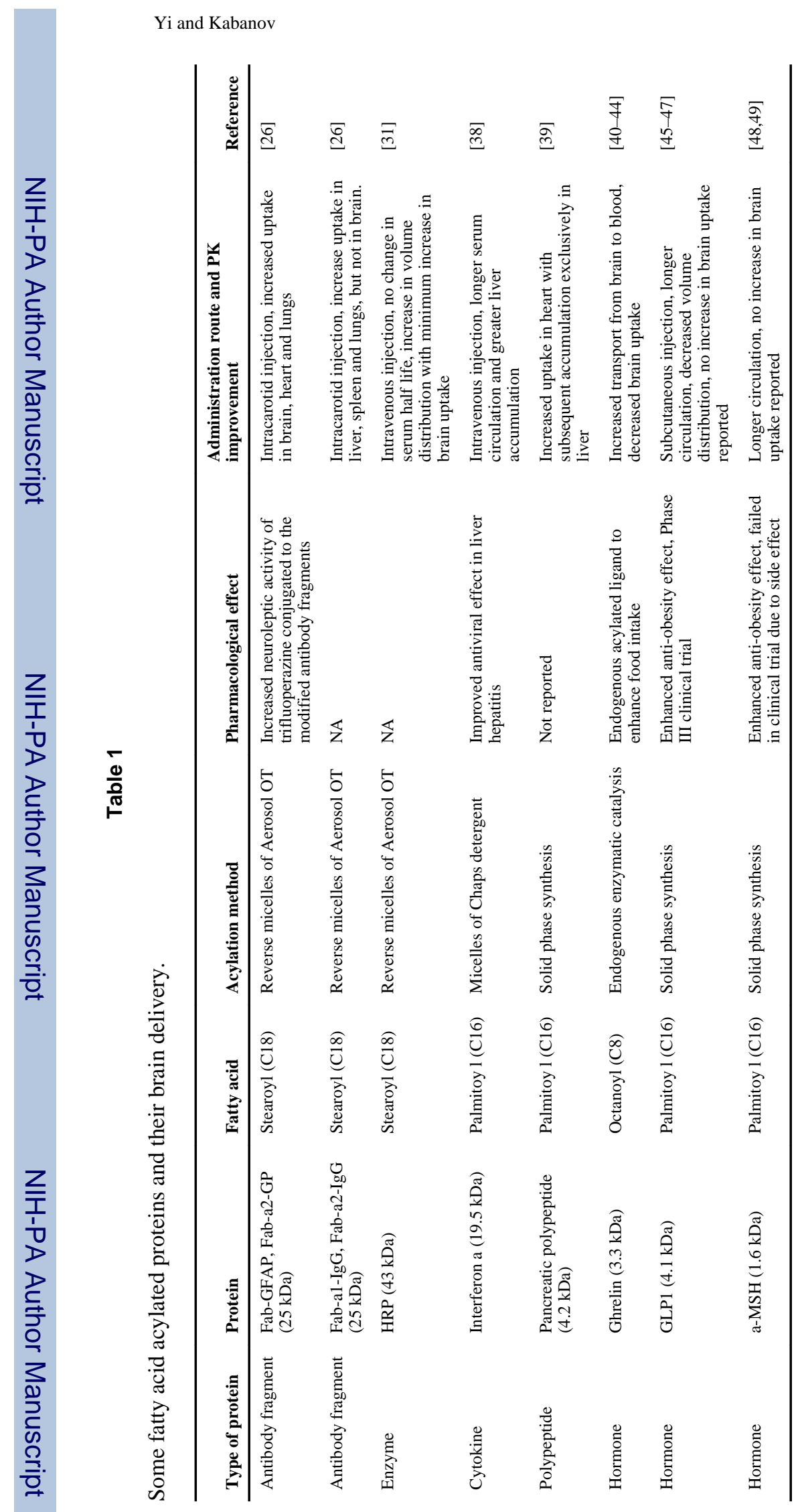

J Drug Target. Author manuscript; available in PMC 2014 May 27. 


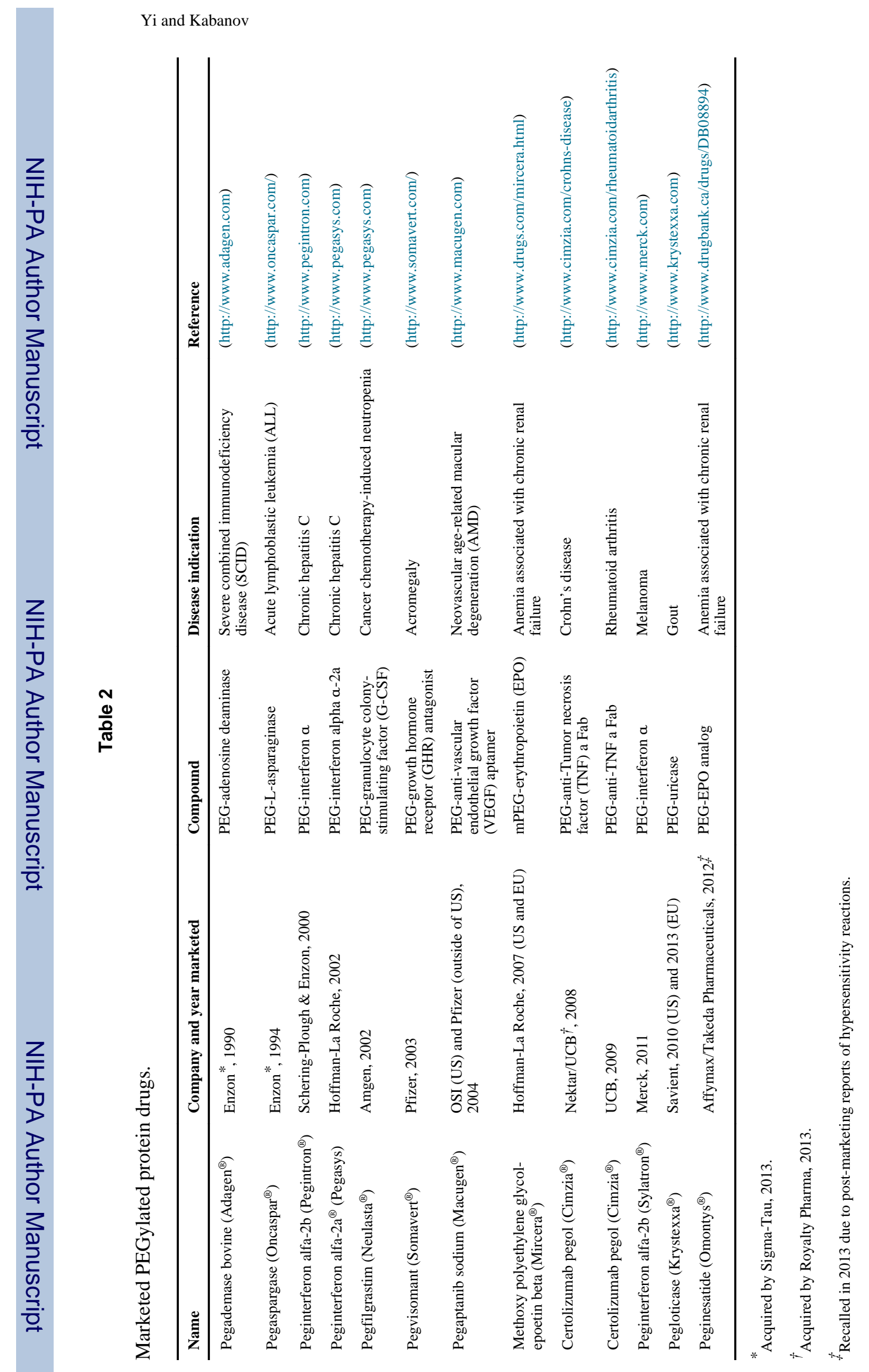

Page 27 


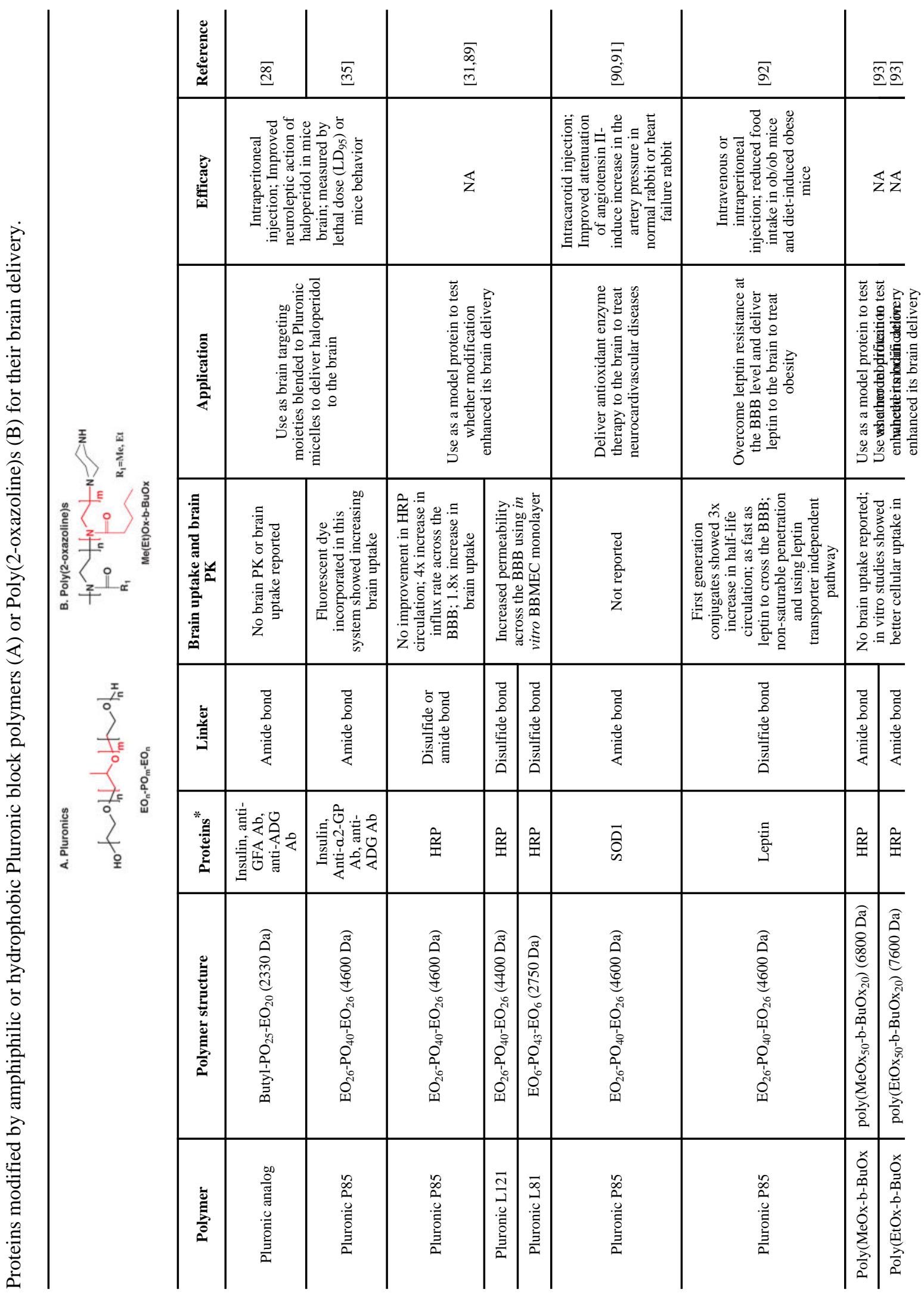




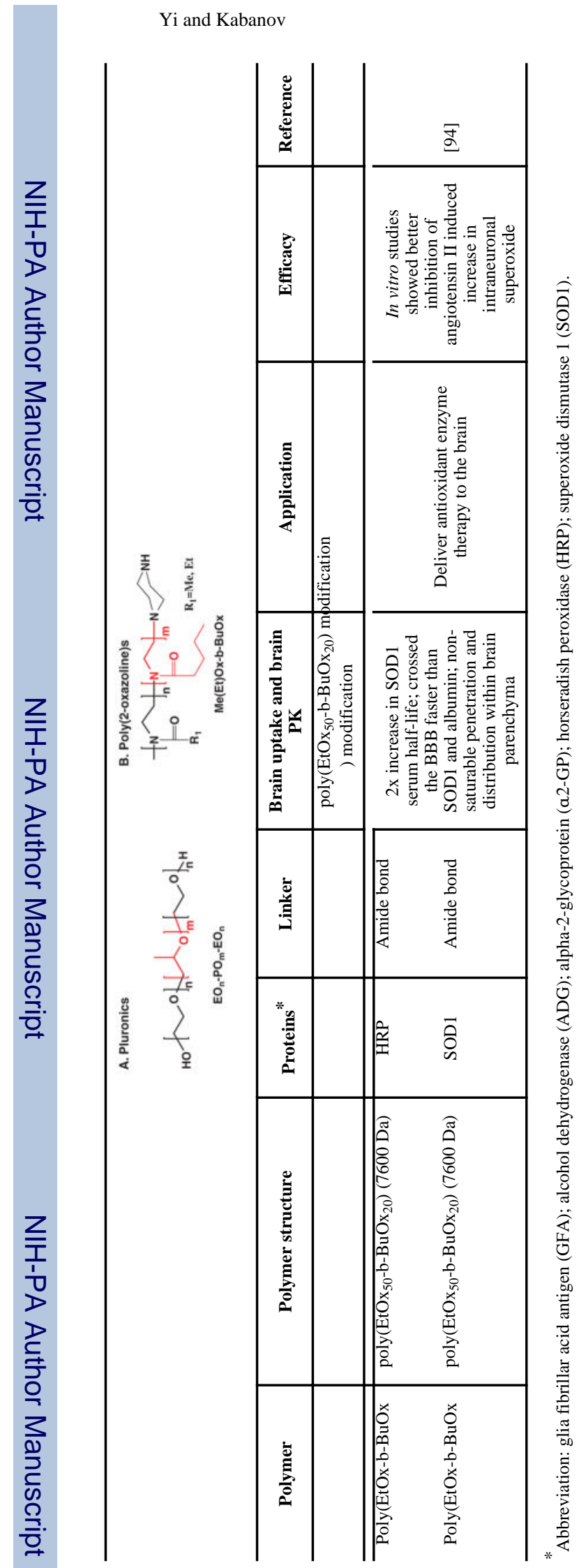

Page 29

J Drug Target. Author manuscript; available in PMC 2014 May 27. 